Case Report

\title{
A Case of Superficial Femoral Arteriovenous Fistula and Severe Venous Stasis Ulceration, Managed with an Iliac Extender Prosthesis
}

\author{
Nicole Ilonzo, Selena Goss, Chun Yang, and Michael Dudkiewicz \\ Mount Sinai St. Luke's-West, New York, NY, USA \\ Correspondence should be addressed to Nicole Ilonzo; nilonzo@chpnet.org
}

Received 22 August 2016; Revised 9 March 2017; Accepted 17 May 2017; Published 20 July 2017

Academic Editor: Muzaffer Sindel

Copyright (C) 2017 Nicole Ilonzo et al. This is an open access article distributed under the Creative Commons Attribution License, which permits unrestricted use, distribution, and reproduction in any medium, provided the original work is properly cited.

\begin{abstract}
Most femoral artery arteriovenous fistulas occur as a result of percutaneous interventions. However, arteriovenous fistulas can occur in the setting of trauma, with resultant consequences such as heart failure, steal syndrome, or venous insufficiency. Indications for endovascular repair in this setting are limited to patients who are at too high risk for anesthesia, have a hostile groin, or would not survive significant bleeding. We report the case of a traumatic femoral arteriovenous fistula, causing severe venous insufficiency and arteriomegaly, in a 58-year-old male, with history of traumatic gunshot wound complicated by popliteal DVT. Surgical options for arteriovenous fistula include open and endovascular repair but this patient's fistula was more suitable for endovascular repair for reasons that will be discussed.
\end{abstract}

\section{Introduction}

This is a case of an arteriovenous fistula causing severe venous insufficiency with ensuant venous stasis ulceration. Venous insufficiency is a disease that affects anywhere from $<1$ to $40 \%$ of females and $<1$ to $17 \%$ of males [1]. Patients with chronic venous insufficiency can develop complications from this disease, with the most severe being venous stasis ulcerations.

\section{Case Presentation}

A 58-year-old male presented to the emergency department with right lower extremity swelling and a large ulceration on his right lateral leg for nearly six years (Figure 1). The patient had been treated in Guyana with topical agents and dressing changes, without improvement. In the $\mathrm{ED}$, right lower extremity duplex demonstrated popliteal vein thrombosis as well as traumatic fistula between superficial femoral vein and superficial femoral artery. Duplex ultrasound also showed distal femoral vein to measure $4.36 \mathrm{~cm} \mathrm{AP,} \mathrm{mid} \mathrm{femoral} \mathrm{vein}$ $1.12 \mathrm{~cm}$, and an enlarged lymph node noted in the groin measuring $4.56 \times 1.60 \mathrm{~cm}$. CT angiogram of the abdomen, pelvis, and lower extremities showed right superior femoral arteriovenous fistula and a tortuous right common iliac artery that may be causing a May Thurner's type compression of the $\mathrm{R}$ common iliac vein (Figure 2).

Patient subsequently underwent bilateral extremity angiogram and selective catheterization of the right common iliac artery via retrograde left femoral approach. Angiogram revealed a patent but enlarged right common femoral artery, a patent right profunda artery, and a patent and enlarged right superficial femoral artery (SFA) with a distal arteriovenous (AV) fistula connecting the superficial femoral artery to the femoral vein with venous flow upwards (Figure 3). On pelvic imaging, there also appeared to be very late venous filling possibly of a venous malformation, which was not seen on previous imaging (Figure 4). There was a large venous aneurysm just distal to the fistulous tract. The remainder of the arterial outflow was normal giving rise to a patent popliteal artery and patent tibial trifurcation.

The decision was made to pursue endovascular repair of the patient's fistula. Given concerns that the SFA was so enlarged and at risk for significant hemorrhage, a superficial femoral artery cutdown was performed (Figure 5). The SFA was dissected free from its surrounding structures. The anterior wall of the SFA was punctured in an antegrade 


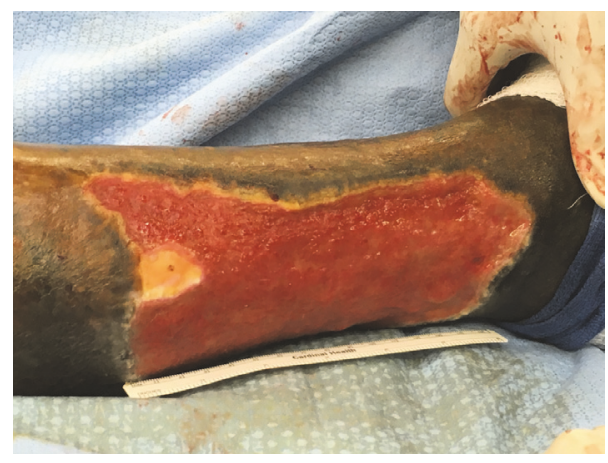

FIgURE 1: Right lateral leg venous stasis ulcer.

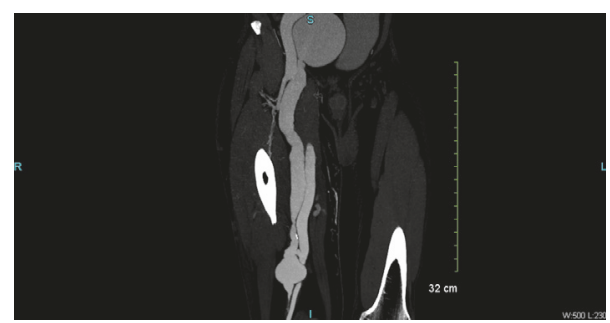

FIGURE 2: CT angiogram showing a superficial femoral arteriovenous fistula with arteriomegaly of the right external iliac artery.

fashion and a 12-French sheath was then placed. There was some bleeding around the 12-French sheath which required clamping of the proximal superficial femoral artery with a vascular clamp. A Gore iliac branch endoprosthesis which measured $10 \mathrm{~mm}$ distally $16 \mathrm{~mm}$ proximally for a length of $7 \mathrm{~cm}$ was opened and deployed in standard fashion across the arteriovenous fistula. It was postdilated using an angioplasty balloon. After postdilation angioplasty there was good apposition against the wall and the fistula filled very slowly via collaterals and not via inline flow (Figure 6). In addition, the patient maintained his outflow via the popliteal artery. Split thickness graft was placed over the ulcer and negative pressure therapy was utilized. The VAC was taken down and there was excellent take of the skin graft. Patient has subsequently undergone Unna booth therapy and the wound has healed completely after 3 months (Figure 7).

\section{Discussion}

The scoring system used to classify and stage venous insufficiency is called the clinical manifestations, etiological factors, anatomical distribution, and pathophysiological conditions classification (CEAP classification) [2,3]. This patient, with a CEAP classification of C6 for active venous ulceration, required surgical intervention. The key to treatment of this venous stasis ulceration was to interrupt the fistula [4].

Traumatic arteriovenous fistulae can be repaired by open or endovascular approaches $[5,6]$. This patient's fistula was best managed with an endovascular approach but there were limitations given the proximal and distal landing zones were significantly different in size. Using a standard Viabahn stent

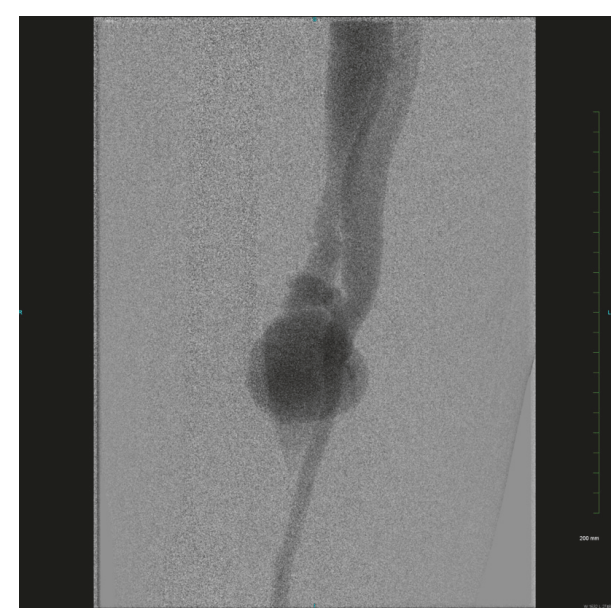

FIGURE 3: Right lower extremity angiogram showing a patent and enlarged right superficial femoral artery with a distal AV fistula connecting the superficial femoral artery to the femoral vein with venous flow upwards.

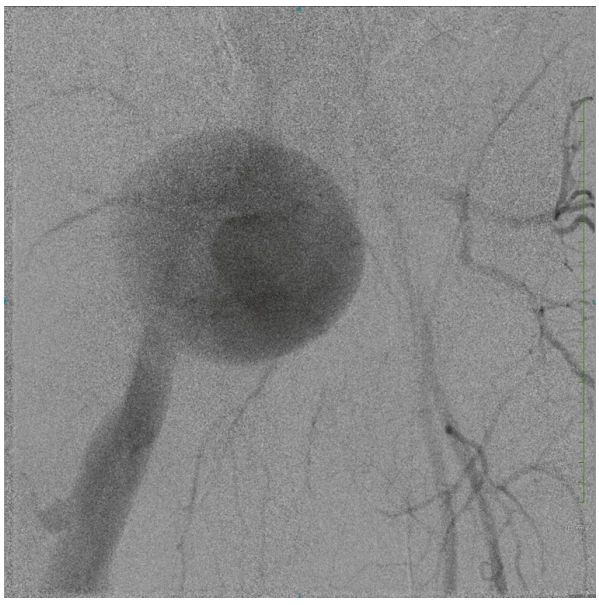

FIGURE 4: Right lower extremity angiogram showing possibility of a venous malformation, which was not seen on previous imaging.

would be a suboptimal choice for this reason. Therefore, the decision was made to use a Gore Excluder Iliac branch endoprosthesis, which could adjust for this asymmetry. As described by the manufacturer, the Gore Excluder Iliac branch endoprosthesis is indicated for treatment of infrarenal artery aneurysms. The graft is exclusively designed for the iliac artery [7]. However, it was used with excellent effect in this context.

Of note, there may be an element of residual venous hypertension secondary to compression of the right external iliac vein by the hypertrophied right external iliac artery. We anticipate further healing of his venous stasis ulcer now that the patient's venous insufficiency is largely corrected with the stent. However, if his venous disease did not seem to improve significantly, we would have attempted to treat the external iliac vein compression with a stent in hopes of providing patency to the vein. 


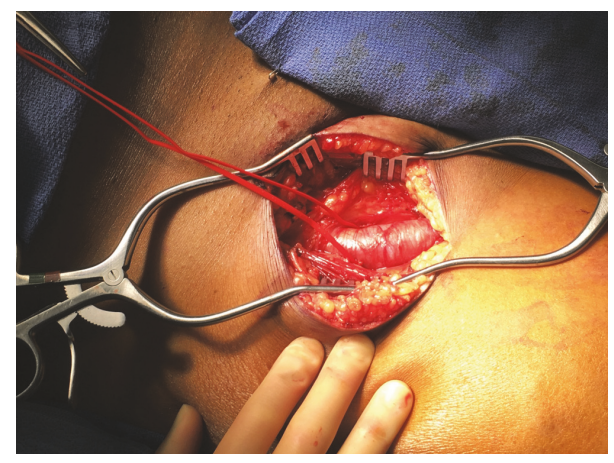

FIGURE 5: A superficial femoral artery cutdown was performed revealing an enlarged SFA.

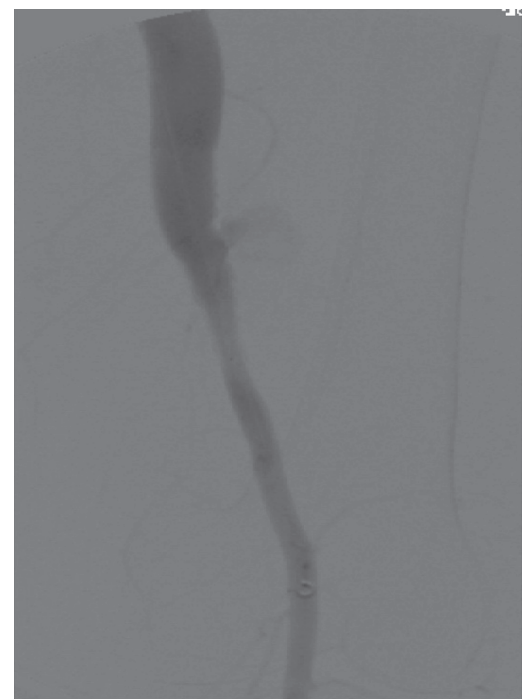

FIGURE 6: Superficial femoral arteriovenous fistula occluded after placement of iliac extender stent.

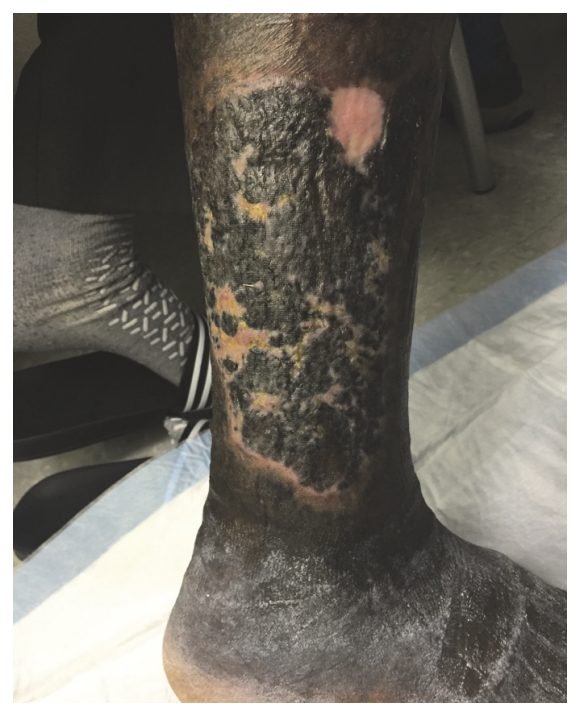

FIGURE 7: Wound healed within 3 months.

\section{Conflicts of Interest}

The authors declare that there are no conflicts of interest regarding the publication of this paper.

\section{References}

[1] J. L. Beebe-Dimmer, J. R. Pfeifer, J. S. Engle, and D. Schottenfeld, "The epidemiology of chronic venous insufficiency and varicose veins," Annals of Epidemiology, vol. 15, no. 3, pp. 175-184, 2005.

[2] S. Krishnan and S. C. Nicholls, "Chronic venous insufficiency: clinical assessment and patient selection," Seminars in Interventional Radiology, vol. 22, no. 3, pp. 169-177, 2005.

[3] B. Vasudevan, "Venous leg ulcers: Pathophysiology and Classification," Indian Dermatology Online Journal, vol. 5, no. 3, p. 366, 2014.

[4] R. Chiesa, E. M. Marone, C. Limoni, M. Volontè, and O. Petrini, "Chronic venous disorders: correlation between visible signs, symptoms, and presence of functional disease," Journal of Vascular Surgery, vol. 46, no. 2, pp. 322-330, 2007.

[5] E. Aslim, "Traumatic arteriovenous fistulae 25 years after gunshot injury," European Journal of Vascular and Endovascular Surgery, vol. 52, no. 3, p. 316, 2016.

[6] P. C. Thompson, B. W. Ullery, D. Fleischmann, and V. Chandra, "Novel approach to a giant external iliac vein aneurysm secondary to posttraumatic femoral arteriovenous fistula," Vascular and Endovascular Surgery, vol. 49, no. 5-6, pp. 148-151, 2015.

[7] "Instructions for use for GORE EXCLUDER AAA Endoprosthesis," https://www.goremedical.com/products/excluder-ifu/ instructions. 


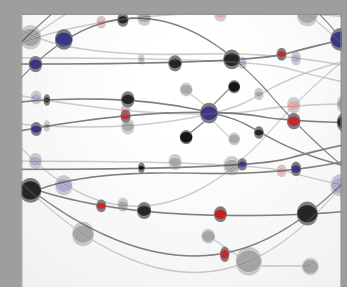

The Scientific World Journal
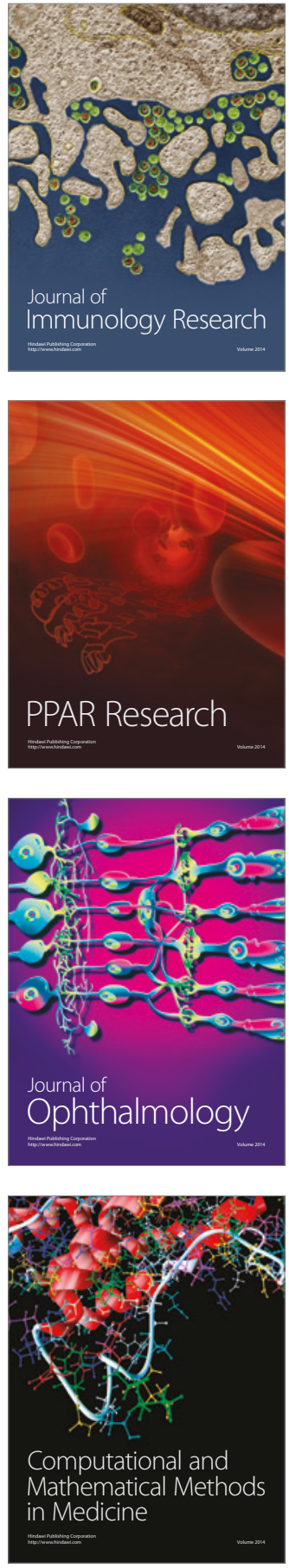

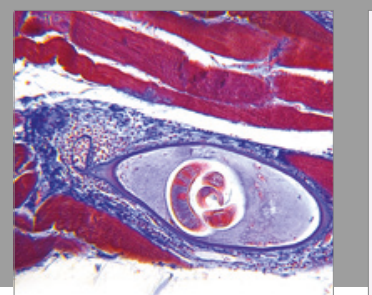

Gastroenterology Research and Practice
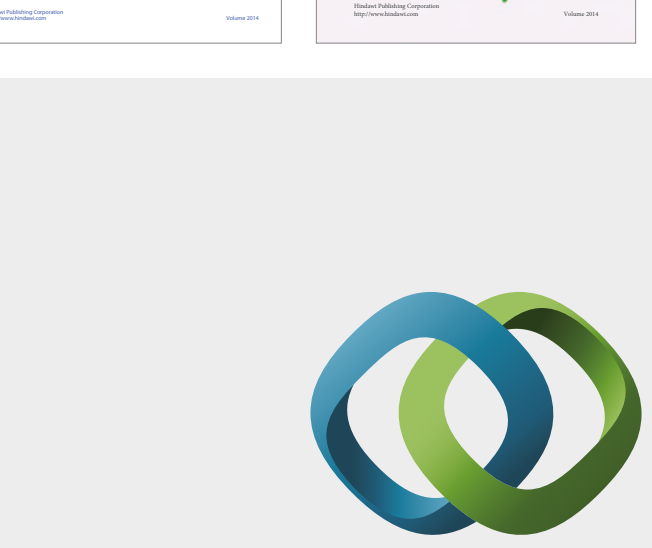

\section{Hindawi}

Submit your manuscripts at

https://www.hindawi.com
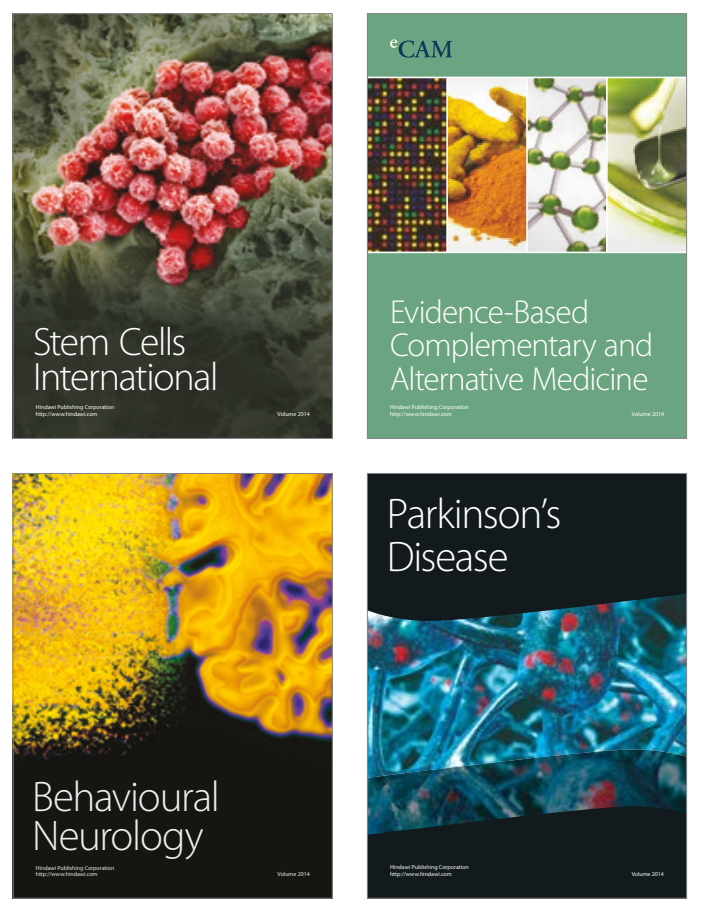
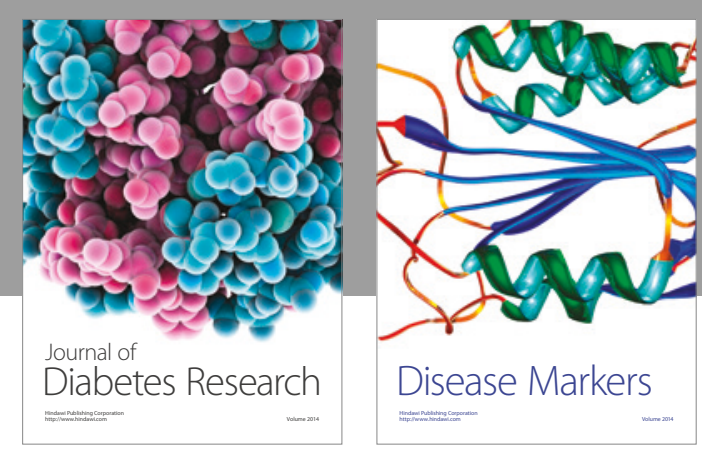

Disease Markers
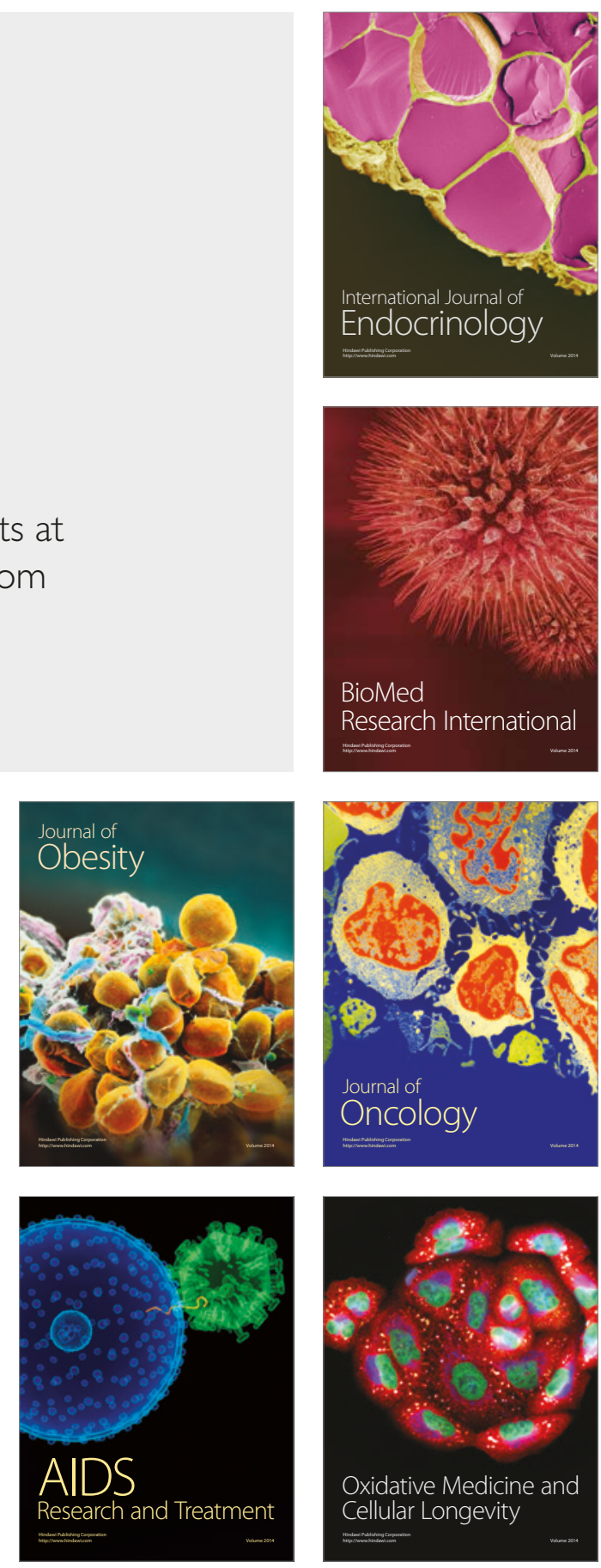